Témoigner Témoigner. Entre histoire et mémoire

Getuigen Revue pluridisciplinaire de la Fondation Auschwitz

Violences radicales en scène

\title{
Colombie - À Bogota, le street art contre l'oubli
}

\section{Rachel Nef}

\section{(2) OpenEdition}

\section{Journals}

Édition électronique

URL : https://journals.openedition.org/temoigner/3616

DOI : 10.4000/temoigner.3616

ISSN : 2506-6390

Éditeur :

Éditions du Centre d'études et de documentation Mémoire d'Auschwitz, Éditions Kimé

Édition imprimée

Date de publication : 1 octobre 2015

Pagination : 192-195

ISSN : 2031-4183

Référence électronique

Rachel Nef, «Colombie - À Bogota, le street art contre l'oubli », Témoigner. Entre histoire et mémoire [En ligne], 121 | 2015, mis en ligne le 01 octobre 2016, consulté le 04 février 2022. URL : http:// journals.openedition.org/temoigner/3616 ; DOI : https://doi.org/10.4000/temoigner.3616 


\section{Colombie \\ Co \\ À BOGOTA, LE STREET ART CONTRE L'OUBLI}

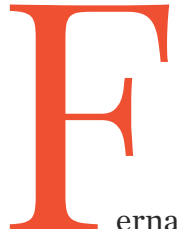

ernando Botero, un des plus grands peintres colombiens, a dit au début du XXI ${ }^{\mathrm{e}}$ siècle : « La violence a commencé à être dans ma tête et un jour, j'ai senti que je devais peindre, déclarer l'horreur qui est la mienne face à ce panorama du pays ${ }^{1}$. »

Comme lui, les artistes de rue de Bogota se sont emparés du thème du conflit armé dans un pays qui se relève doucement de décennies de violence.

Ainsi, en se promenant dans les rues de la capitale colombienne, notre regard est happé par ces fresques murales représentant des familles fuyant leurs villages, des cadavres, mais aussi par les messages de paix, comme un rappel permanent de la violence du conflit qui a eu lieu dans le pays.

En effet, ces trente dernières années, les affrontements mêlant les FARCs ${ }^{2}$, les milices paramilitaires - qui se présentent comme une force de contre-insurrection opposée aux guérillas - et l'armée a fait plus de deux cent mille morts.

Le conflit armé interne en Colombie a été marqué par des atteintes aux droits humains généralisées et systématiques, parmi lesquelles homicides ou exécutions extrajudiciaires, disparitions forcées, actes de torture, déplacements forcés, enlèvements et violences sexuelles. Ces exactions ont été perpétrées tant par les forces de sécurité et les paramilitaires, agissant seuls ou de concert, que par les groupes de guérilla.
Aujourd'hui, la guérilla est grandement affaiblie elle ne compterait plus que huit mille membres encore actifs - et nombre des paramilitaires ont été désarmés. Le conflit interne ne touche pas l'ensemble du pays mais affecte certaines régions en particulier (les provinces du Sud et de l'Est notamment) avec des degrés d'impact divers sur les autres régions.

Mais le sujet reste omniprésent dans la société colombienne.

Chaque journal télévisé s'ouvre sur l'avancée des négociations, les matchs de football de la Copa America (l'équivalent de notre Euro) sont interrompus par des spots du ministère de la Défense incitant les guérilleros à la démobilisation, et la presse écrite relaye inlassablement les attentats imputés aux FARCs et les contre-offensives gouvernementales.

Dans le même temps, la Colombie cherche à oublier les stigmates de son passé, à effacer cette image qui la résume aux conflits armés, au trafic de drogue, à la violence sommaire et aux enlèvements. On peut voir à la télévision des spots gouvernementaux vantant la paix retrouvée ou la réussite de certaines villes comme Medellín qui sont parvenues à éradiquer presque totalement la violence.

Dans un pays qui connaît une course effrénée au développement du tourisme, à la croissance économique, à la modernité et à la sécurité, certains gravent 


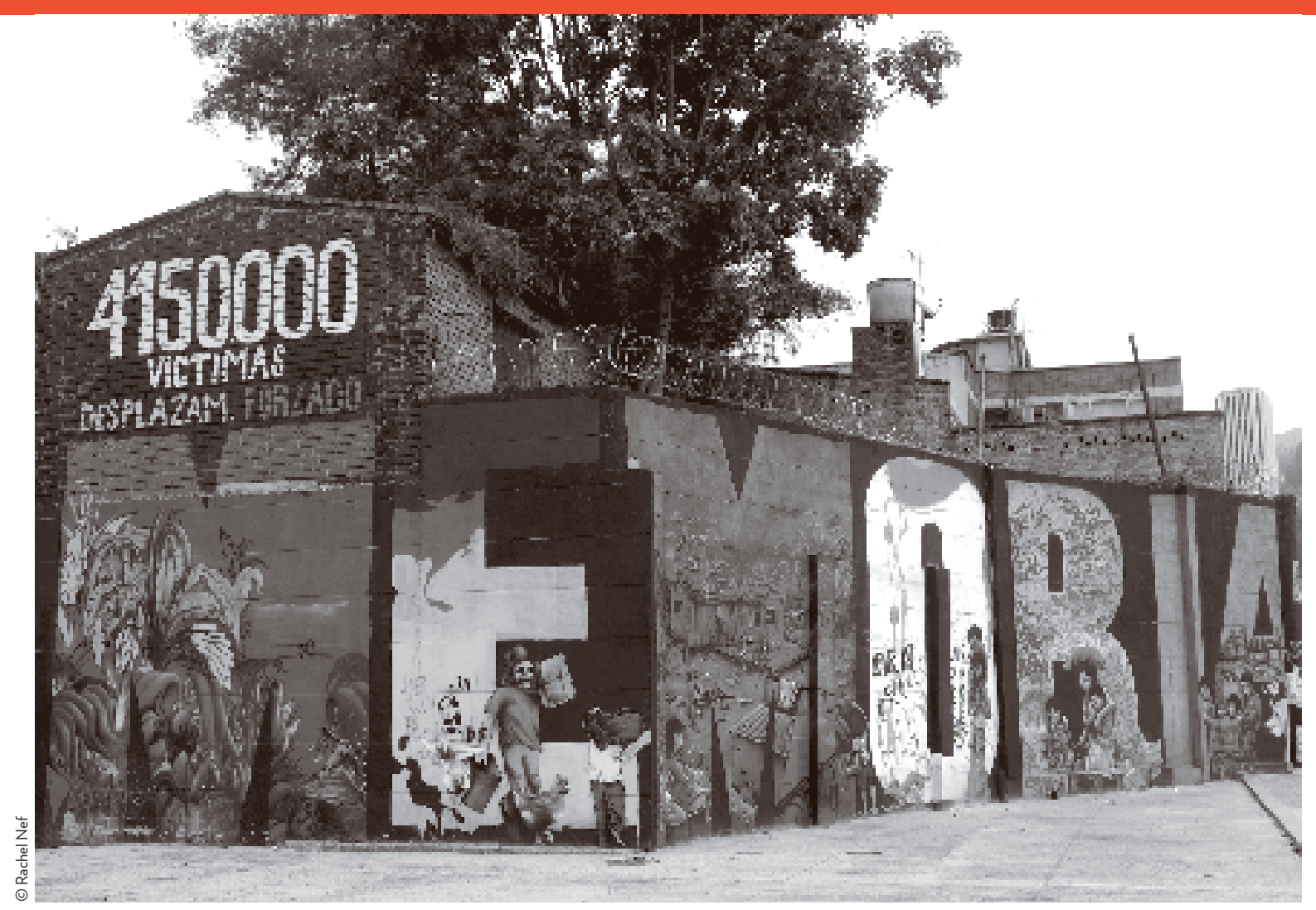

- Photo 1.

sur les murs les chiffres des morts, des disparus, dessinent les ravages de la violence pour qu'on n'oublie pas ce qui s'est passé ici. Le « devoir de mémoire » s'affiche sans compromission à l'angle des rues.

Les villes d'Amérique du Sud sont marquées depuis longtemps par une tradition d'expression populaire graphique politique et critique.

Inspiré du muralisme mexicain, né dans les années 1920 après la révolution afin de diffuser largement un message politique et social, le street art joue aujourd'hui un rôle important à travers le continent. On voit, par exemple, à Buenos Aires des graffitis mettant en scène les mères de la place de Mai - dont les enfants ont disparu pendant la dictature militaire - avec l'inscription « Ni pardon, ni oubli » ou des « siluetazo » (silhouettes de personnes disparues) disséminés dans les rues de la capitale argentine.

$\mathrm{Au}$ Chili également, les célèbres graffitis de la ville de Valparaiso sont nés avec une idée d'engagement politique.
Ces œuvres communiquent avec le citadin, et tentent de l'interpeller. Elles constituent une prise de parole engagée, une forme de résistance, faisant de la ville un territoire habité et politisé.

Les artistes de street art colombiens tentent de percer l'abcès des maux de leur société. Comme beaucoup de Colombiens, ils ont l'impression que l'État refuse la transparence et que l'accent n'est mis que sur les négociations de paix.

En effet, les scandales se sont succédé, des liens étroits entre l'armée régulière et les paramilitaires ont été avérés ${ }^{3}$, ainsi que les liens entre une partie importante de la classe politique et les paramilitaires, aggravant le manque de confiance de la population dans ses représentants politiques.

(1) Fernando Botero, «Botero retrata décadas de violencia en Colombia », El Pais, 4 mai 2004.

(2) Forces Armées Révolutionnaires de Colombie, guérilla marxiste fondée en 1964. 


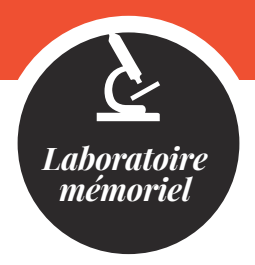

- Photo 2.

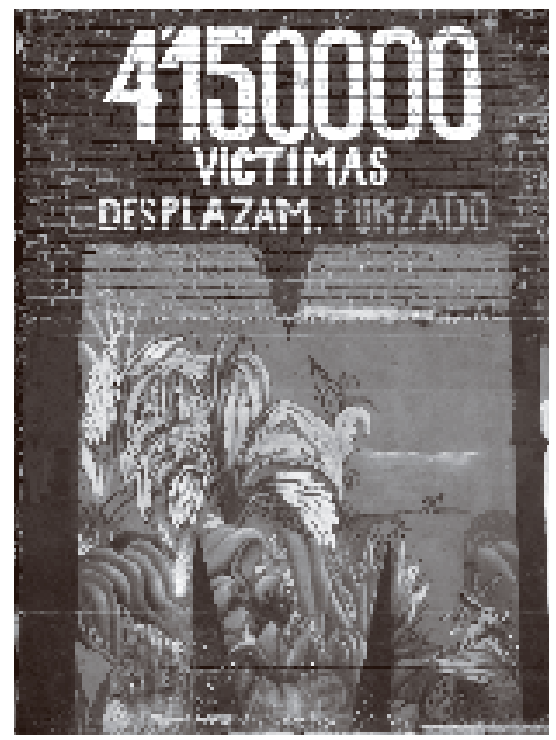

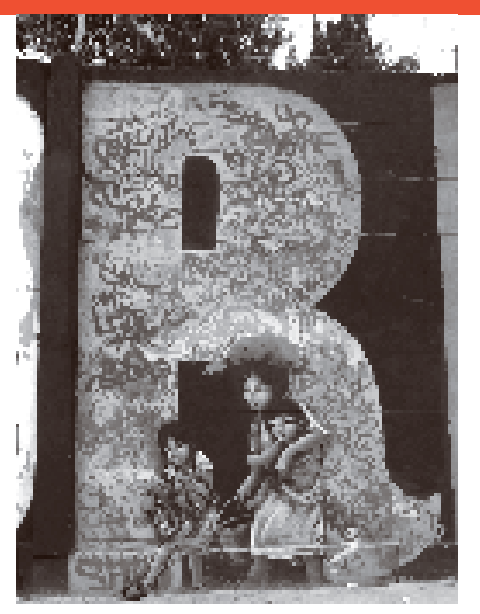

- Photo 3.

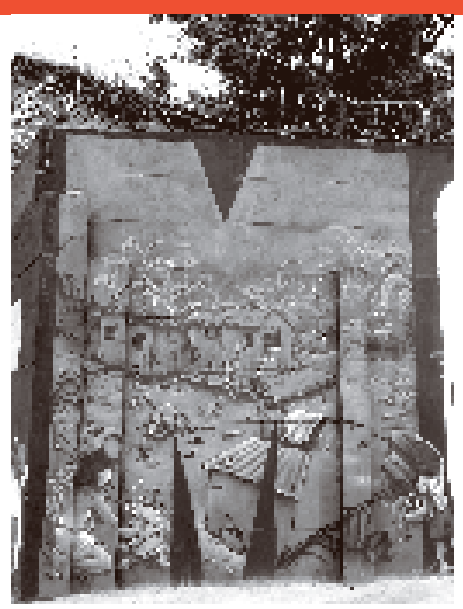

_ Photo 4.

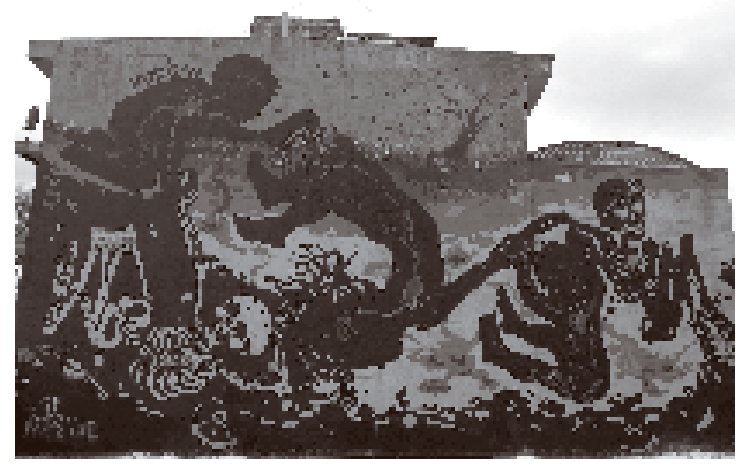

Photo 5

—. Le plus grand scandale de ces dernières années a été appelé « scandale des faux positifs ». Il éclate fin 2008 et désigne la pratique consistant, pour les forces militaires, à abattre des civils avant de les faire passer pour des ennemis de la nation en les affublant d'uniformes des guérilleros. L'objectif de cette pratique est d'améliorer les statistiques (nombre de guérilleros tués), et donc d'obtenir des primes ou des permissions.

De plus, à côté de la guérilla et des paramilitaires, le gouvernement colombien est également responsable d'un nombre important d'exécutions extrajudiciaires et de violations des droits de l'homme.

Dans ce contexte, les graffitis sont pour certains le meilleur moyen de faire passer des messages au plus grand nombre, d'exprimer leur colère, de faire bouger les choses, de lutter contre l'oubli (voir la photo 1, un graffiti illustrant les différents aspects du conflit intitulé « Memoria»).
En Colombie, plusieurs graffitis dénoncent (photos 2 et 3) les déplacements massifs de populations liés au conflit, qui auraient touché 5,7 millions de personnes selon le Haut Commissariat aux Refugiés des Nations Unies $^{4}$.

Selon les chiffres du Comité international de la Croix Rouge, la majorité de ces personnes déplacées (52\%) sont des mineurs (comme illustré sur le graffiti de la photo 3). Dans de nombreux cas, des groupes illégaux, en particulier paramilitaires et narcotrafiquants s'approprient les terrains laissés par les personnes déplacées : cette situation concerne plus de 5 millions d'hectares dans le pays. Ainsi, sans possibilité de réinstallation les déplacés sont venus grossir les rangs des populations en situation de précarité dans les faubourgs des grandes villes.

La paix est également un thème récurrent (photos 6, 7, 8 et 9), avec des graffitis accompagnés de phrases 


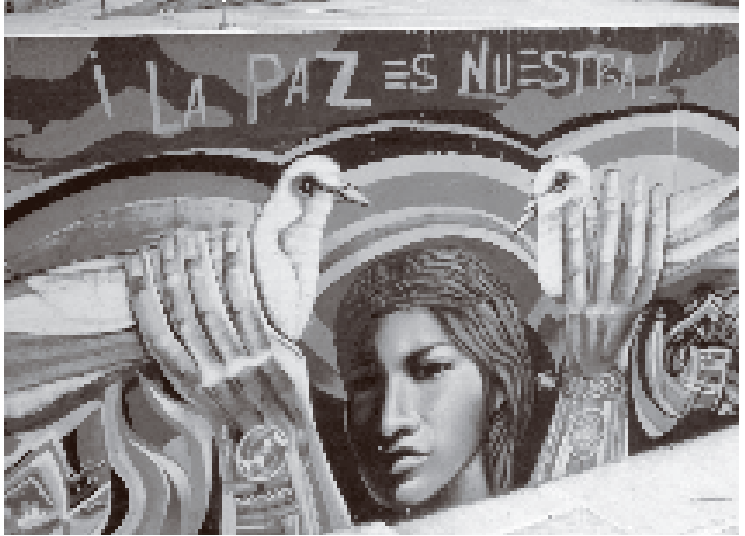

- Photo 6.

- Photo 8.

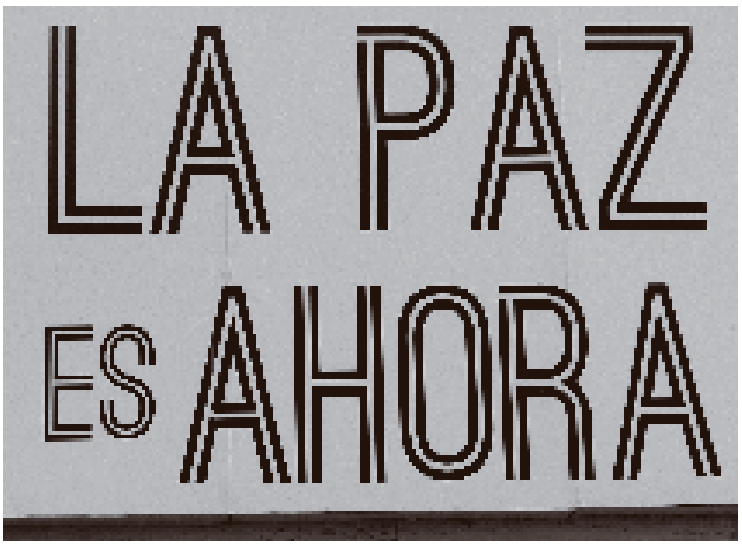

comme « la paz es nuestra » - la paix est à nous ou « La paz es ahora » - la paix est maintenant.

En effet, des négociations de paix sont en cours entre les FARCs et le gouvernement du président Juan Manuel Santos depuis novembre 2012, mais elles achoppent sur le point le plus délicat, car contrairement à ce qui s'est passé pour les chefs des milices paramilitaires, les guérilleros ne veulent pas faire de la prison pour les crimes de guerre ou les violations des droits de l'homme commis au cours du conflit.

En 2005, la loi dite de « justice et paix » imposait aux paramilitaires des peines maximales de huit ans, à condition de se démobiliser et de confesser leurs crimes, satisfaisant ainsi le besoin de vérité des victimes.

Il est vrai que les paramilitaires ont été les principaux responsables des homicides, actes de tortures et disparitions depuis leur pénétration au sein du conflit.

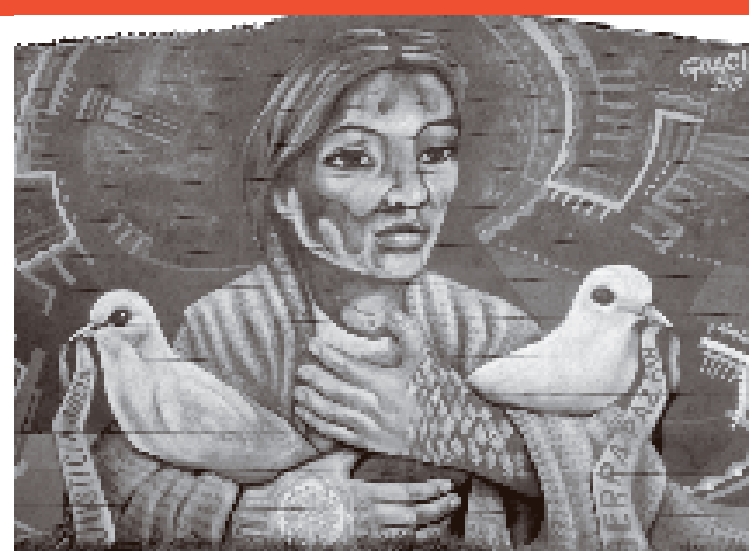

- Photo 7.

- Photo 9

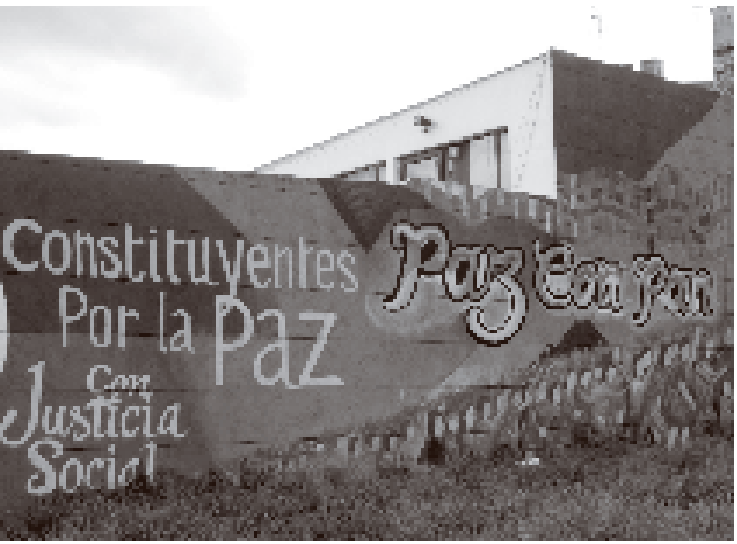

Les FARCs, quant à eux, refusent d'envisager des peines de prison, même réduites. Or si les guérilleros étaient amnistiés, comment faire admettre aux militaires poursuivis pour crimes de guerre de payer, seuls, le prix de ces tractations?

Les négociateurs sont confrontés au dilemme de concilier la volonté de paix et l'exigence de justice.

Les graffitis témoignent de cette aspiration à la réconciliation, mais les FARCs ont annoncé dernièrement la fin de la trêve " unilatérale et indéfinie » qu'ils avaient décrétée fin décembre 2014. Depuis cette annonce des FARCs, les affrontements mortels et les raids du gouvernement sont quasi quotidiens.

La paix attendra.

Rachel Nef

(3) Rapport de Human Rights Watch, 2000.

(4) Chiffres du HCR au 30 juin 2014. 